\title{
Liver Alkaline Phosphatase to Total Alkaline Phosphatase Ratio Measurement
}

National Cancer Institute

\section{Source}

National Cancer Institute. Liver Alkaline Phosphatase to Total Alkaline Phosphatase Ratio Measurement. NCI Thesaurus. Code C147296.

The determination of the ratio of liver-specific alkaline phosphatase compared to total alkaline phosphatase present in a sample. The measurement may be expressed as a ratio or percentage. 